\title{
Urinary undiversion from a sigma-rectum pouch to a cutaneous urinary stoma as a treatment for severe metabolic disorders post-radical cystectomy: A case report
}

\author{
HUA SHEN, KAI LIAO, WEILI WU, HONGBO YU and HONGFEI WU \\ Department of Urology, BenQ Medical Center, The Affiliated BenQ Hospital of \\ Nanjing Medical University, Nanjing, Jiangsu 210019, P.R. China
}

Received January 28, 2019; Accepted October 2, 2019

DOI: $10.3892 /$ etm.2019.8111

\begin{abstract}
A total of six male patients, who had undergone radical cystectomy and sigma-rectum pouch surgery due to bladder cancer (2-5 years previously), developed hyperchloremic metabolic acidosis, hypokalemia and renal dysfunction. The patients underwent urinary undiversion surgery (the pouch was isolated from the intestinal tract, abdominal ostomy was performed, and the sigmoid colon and rectum were reconnected) and blood gas and electrolyte analysis and renal function were compared pre- and post-surgery. Blood hydrocarbonate levels significantly improved 3 months post-surgery compared with the preoperative levels $(17.90 \pm 4.12$ vs. $7.57 \pm 4.25 ; \mathrm{P}=0.026)$. At 6 months post-surgery, blood $\mathrm{pH}(7.36 \pm 0.04$ vs. $7.16 \pm 0.08 ; \mathrm{P}=0.028)$ and potassium levels $(3.95 \pm 0.38$ vs. $3.12 \pm 0.21 ; \mathrm{P}=0.032)$ were found to have improved significantly compared with the pre-surgery levels, and remained normal. Serum creatinine levels decreased significantly from the preoperative levels at 6 months post-surgery $(213.00 \pm 44.85$ vs. $304.67 \pm 55.58 ; \mathrm{P}=0.028)$. Serum chlorine $(99.17 \pm 2.75$ vs. $110.90 \pm 4.38 ; \mathrm{P}=0.038)$ significantly improved until 3 years post-surgery. The results of this case report indicated that urinary undiversion from a sigma-rectum pouch to a cutaneous urinary stoma that separates the pouch and intestine may be a beneficial treatment for post-sigma-rectum pouch surgery acidosis and electrolyte disturbances.
\end{abstract}

\section{Introduction}

Radical cystectomy is the standard treatment for localized muscle-invasive bladder cancer (MIBC) $(1,2)$. Urinary

Correspondence to: Dr Hua Shen or Dr Hongfei Wu, Department of Urology, BenQ Medical Center, The Affiliated BenQ Hospital of Nanjing Medical University, 71 Hexi Avenue, Jianye, Nanjing, Jiangsu 210019, P.R. China

E-mail: shnjmu@hotmail.com

E-mail: willis.wu@benqmedicalcenter.com

Key words: urinary diversion, urinary undiversion, metabolic disorder, sigma-rectum pouch, bladder cancer diversion methods post-radical cystectomy include abdominal, urethral and rectosigmoid diversions. Urinary diversion has evolved along three distinct paths: Incontinent cutaneous diversion (conduit); continent cutaneous diversion (pouch); and, most recently, continent urinary diversion to the intact native urethra (neobladder, orthotopic reconstruction) (2). Continent urinary diversion has been revealed to improve the quality of life of patients post-cystectomy and is preferred by most urologists and patients (3). Conduit urinary diversions fall into two categories: Those using the small bowel, including the jejunum or ileum; and those using a part of the colon (4).

The sigma-rectum pouch (Mainz pouch II), first described by Fisch et al in 1993 (5), is a relatively safe and simple system for urinary diversion. The procedure allows for continent urinary diversion into a low-pressure, high-capacity reservoir created using the rectosigmoid colon (6). Hyperchloremic acidosis and electrolyte disturbances that lead to metabolic disorders (owing to the absorption of urinary metabolites by the intestinal mucosa) are one possible complication of sigma-rectum pouch surgery and require treatment with oral medication $(5,7,8)$. Patients with severe metabolic disorders, which do not respond to drugs, can suffer extensive damage to renal function that eventually threatens their life (8).

Between July 2011 and April 2015, a total of six male patients afflicted with recurrent hyperchloremic metabolic acidosis, hypokalemia and renal dysfunction after receiving sigma-rectum pouch surgery, underwent urinary undiversion surgery from a sigma-rectum pouch to a cutaneous urinary stoma at BenQ Medical Center, with satisfactory results. All patients were informed of the risk of unpredictable surgical outcomes and complications prior to the surgery. On agreeing to participate they signed informed consent forms and the surgery was approved by the Medical Ethics Review Committee of BenQ Medical Center (approval no. 2011072102).

\section{Case report}

Patient data. A total of six male patients, aged 58-82 years (median age, 70 years), underwent radical cystectomy and sigma-rectum pouch surgery due to MIBC 2-5 years prior to admission to the Urology Department of BenQ Medical Center. Recurrent fatigue and anorexia 1-4 years 
post-operatively had been complained by all patients. Blood gas analysis (WERi-STAT300; Abbott Pharmaceutical Co., Ltd.) and biochemical tests (Bs-390; MINDRAY Medical International Co., Ltd.) indicated hyperchloremic metabolic acidosis (hydrocarbonate $<21 \mathrm{mmol} / \mathrm{l}$; $\mathrm{pH}<7.35$; chlorine $>106 \mathrm{mmol} / \mathrm{l}$ ) and hypokalemia (potassium <3.5 mmol/l), with two patients additionally suffering from hypocalcemia (calcium $<2.1 \mathrm{mmol} / \mathrm{l}$ ). Oral administration of sodium bicarbonate ( $1.0 \mathrm{~g}$; three times per day) and potassium citrate ( $1.45 \mathrm{~g}$; three times per day) led to a poor therapeutic effect in all patients, who needed additional intravenous bicarbonate (2-5 $\mathrm{mmol} / \mathrm{kg}$ ) and potassium salt (40-60 mmol/day) supplements to correct the acidosis and hypokalemia. The interval requiring intravenous rehydration was gradually shortened. In one case, the patient suffered severe paralytic ileus, leading to loss of consciousness. At 1 week prior to the operation, the arterial blood $\mathrm{pH}$, hydrocarbonate $\left(\mathrm{HCO}^{-}\right)$, base excess, serum potassium level, chlorine, urea nitrogen and creatinine were $7.16 \pm 0.08$ (normal range $7.35-7.45$ ), $7.57 \pm 4.25 \mathrm{mmol} / 1$ (normal range $21-26 \mathrm{mmol} / \mathrm{l}$ ), $-19.68 \pm 4.85 \mathrm{mmol} / \mathrm{l}$ (normal range -3-3 mmol/l), 3.12 $\pm 0.21 \mathrm{mmol} / 1$ (normal range 3.5-5.5 mmol/l), $110.90 \pm 4.38 \mathrm{mmol} / \mathrm{l}$ (normal range 96-106 $\mathrm{mmol} / \mathrm{l}$ ), $20.15 \pm 3.77 \mathrm{mmol} / 1$ (normal range $3.2-7.1 \mathrm{mmol} / \mathrm{l}$ ) and $304.67 \pm 55.58 \mu \mathrm{mol} / 1$ (normal range 53-106 $\mu \mathrm{mol} / \mathrm{l}$ ), respectively. Ultrasound revealed two cases of mild hydronephrosis (renal sinus separated $21 \mathrm{~mm}$ ), three cases of moderate hydronephrosis (renal sinus separated $32-38 \mathrm{~mm}$ ) and one of unilateral severe hydronephrosis (renal sinus separated $45 \mathrm{~mm}$ ). Two patients suffered retrograde infection and were treated with unilateral nephrostomy and nephrectomy, respectively.

Preoperative preparation. At 1 week prior to the operation, intravenous infusion of $5 \%$ sodium bicarbonate and $10 \%$ potassium chloride solutions was administered to treat acidosis and hypokalemia. Dynamic blood gas analysis and electrolyte and renal function assessments were carried out to monitor patient status. From 2 days prior to the surgery, the patients were allowed only a liquid diet. Levofloxacin $(500 \mathrm{mg}$ ) and tinidazole $(1,000 \mathrm{mg})$ were administered orally. A cleansing enema was organized the night prior to the surgery. Intravenous infusion of $2.0 \mathrm{~g}$ ceftriaxone sodium was used with general anesthesia to prevent infection.

Operation procedure. Pouch ostomy on the abdominal wall and sigmoid-rectal anastomosis were performed under combined intravenous and inhalation anesthesia (propofol $2.0 \mathrm{mg} / \mathrm{kg}$ intravenous for induction; sevoflurane 1.0-2.0 vol\% inhalation and remifentanil $0.3 \mu \mathrm{g} / \mathrm{kg} / \mathrm{min}$ intravenous for maintenance), in the lithotomy position. A lower midline, $2-\mathrm{cm}$ long, abdominal incision was made from below the umbilicus to the symphysis pubis. The pouch, sigmoid colon and rectum were mobilized, and the mesenteric blood supply was carefully protected. The sigmoid colon was cut at the junction of sigmoid colon and pouch using a disposable linear cutter stapler (Sinolinks Medical Innovation, Inc.) and the rectum below the uretero-pouch anastomosis was cut using a disposable curved cutter (Sinolinks Medical Innovation, Inc.; Fig. 1A). End-to-end anastomosis of the sigmoid colon and rectum was performed on the left of the pouch with a tubular anastomat, after dilating the anal sphincter. The integrity of removed bowels, whether the anastomosed intestine was tension-free, and the patency of intestinal anastomosis were assessed. To reinforce the intestinal anastomosis, interrupted seromuscular inverting suture was performed. The pouch was opened ventrally. The ureter-pouch anastomosis was dilated and a 7 Fr single pig-tail stent (Well Lead Medical Co., Ltd.) was implanted for patients with moderate to severe hydronephrosis. The pouch was pulled out of the abdominal wall; interrupted suture was used to suture the peritoneum with serosa and the aponeurosis of obliquus externus abdominis muscle with seromuscular tissue. The entire layer of the opening of the pouch was sutured to the skin and a 26 Fr mushroom catheter (Well Lead Medical Co., Ltd.) was inserted into the pouch for drainage (Fig. 1B).

Post-operative care. Ceftriaxone sodium (2.0 g) and parenteral nutrition were given intravenously in the immediate days postoperatively, until a liquid diet was permitted (4-5 days later). Arterial blood gases, serum electrolytes and renal function were measured 1 week post-operatively. The single J stent was removed 2 weeks post-surgery. An EC two-piece urinary tract ostomy pocket (60 mm; Coloplast, Ltd.) covered the stoma, and the catheter was shortened so as to fit easily into the pocket (Fig. 2), and was replaced monthly.

Follow up. Follow-ups were carried out at 3 and 6 months, 1, 2 , and 3 years post-surgery. Arterial blood gas analysis, serum electrolytes and renal function were monitored without sodium bicarbonate and/or potassium citrate treatment. Preoperative and postoperative data were compared. The quality of life index and general health condition of the patients was evaluated at 1 year post-surgery using the European Organization for Research and Treatment of Cancer Quality of Life Questionnaire (EORTC QLQ) C-30 survey (9).

Statistical analysis. Data are presented as the mean \pm standard deviation. ANOVA of single-factor repeated measurement data was performed to ascertain the significant differences, followed by bonferronis method, between the pre- and post-surgery data using SPSS statistics 20.0 software (IBM Corp.). $\mathrm{P}<0.05$ was considered to indicate a statistically significant difference.

Surgical outcomes. The duration of the surgery was in the range of 230-290 $\mathrm{min}$, averaging to $255.00 \pm 20.74 \mathrm{~min}$. Intraoperative blood loss was in the range of 40-300 ml, averaging to $161.67 \pm 89.09 \mathrm{ml}$. No surgery-related complications, such as dehiscence of the bowel anastomosis, urinary leakage, infections or thrombotic events, were observed.

Data from the blood gas, electrolyte and renal function analysis are shown in Table I. Arterial blood gas analysis indicated: i) No significant difference between the blood $\mathrm{pH}$ 3 months post-surgery and preoperatively, though $\mathrm{pH}$ was found to recover and remain normal (between 7.35 and 7.45) until 6 months later; and ii) the hydrocarbonate and base excess levels were both significantly different at 6 months and 3 years post-surgery compared with the preoperative levels $(\mathrm{P}<0.05)$. At 1-2 years later, the data had reached normal levels, with hydrocarbonate between 21 and $26 \mathrm{mmol} / 1$ and base excess between -3 and $3 \mathrm{mmol} / \mathrm{l}$. 
A

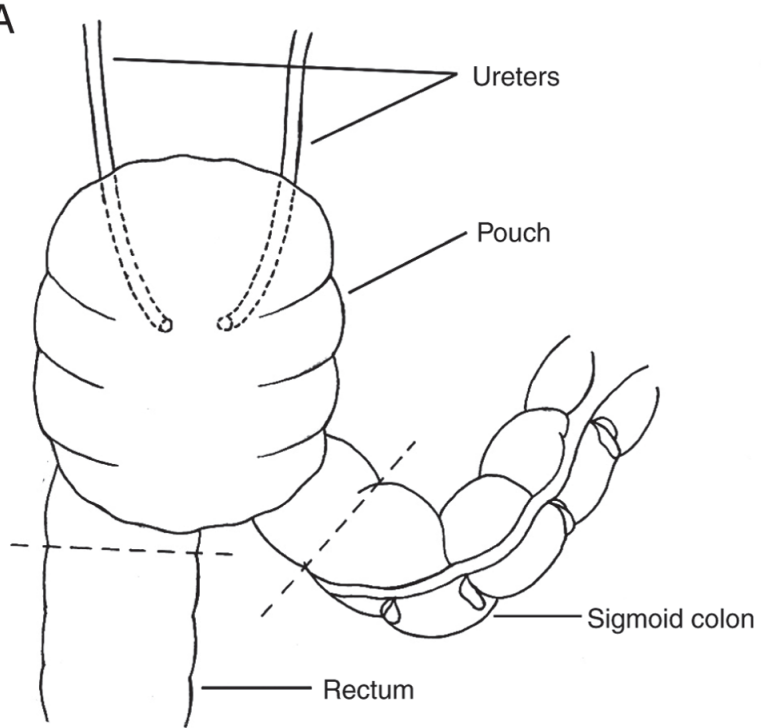

$\mathrm{B}$

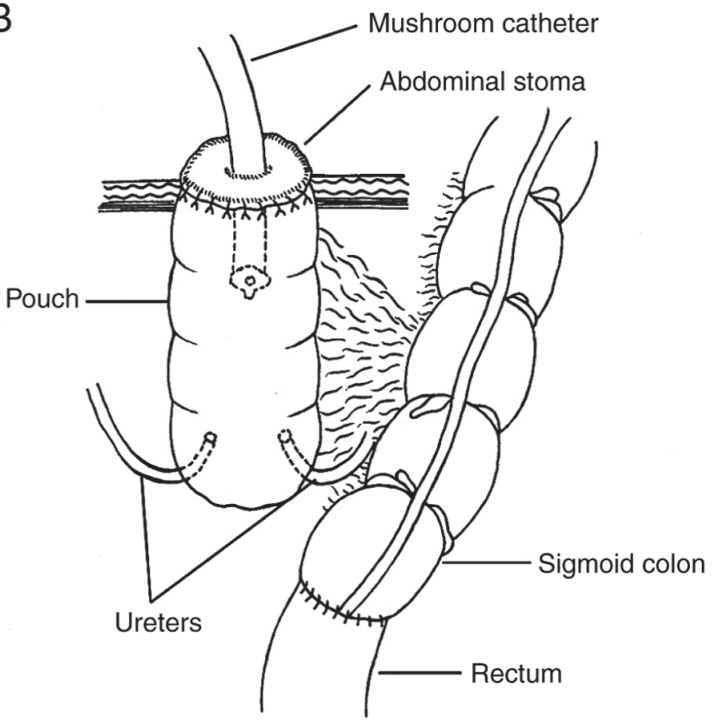

Figure 1. Schematic representation of the pouch ostomy on the abdominal wall and sigmoid-rectal anastomosis. (A) Schematic of the sigma-rectal pouch. Dotted lines indicate incision lines between the pouch and sigmoid colon and rectum. (B) The pouch was isolated from the intestinal tract and an abdominal ostomy was made. The sigmoid colon and rectum were rejoined to recover intestinal continuity.

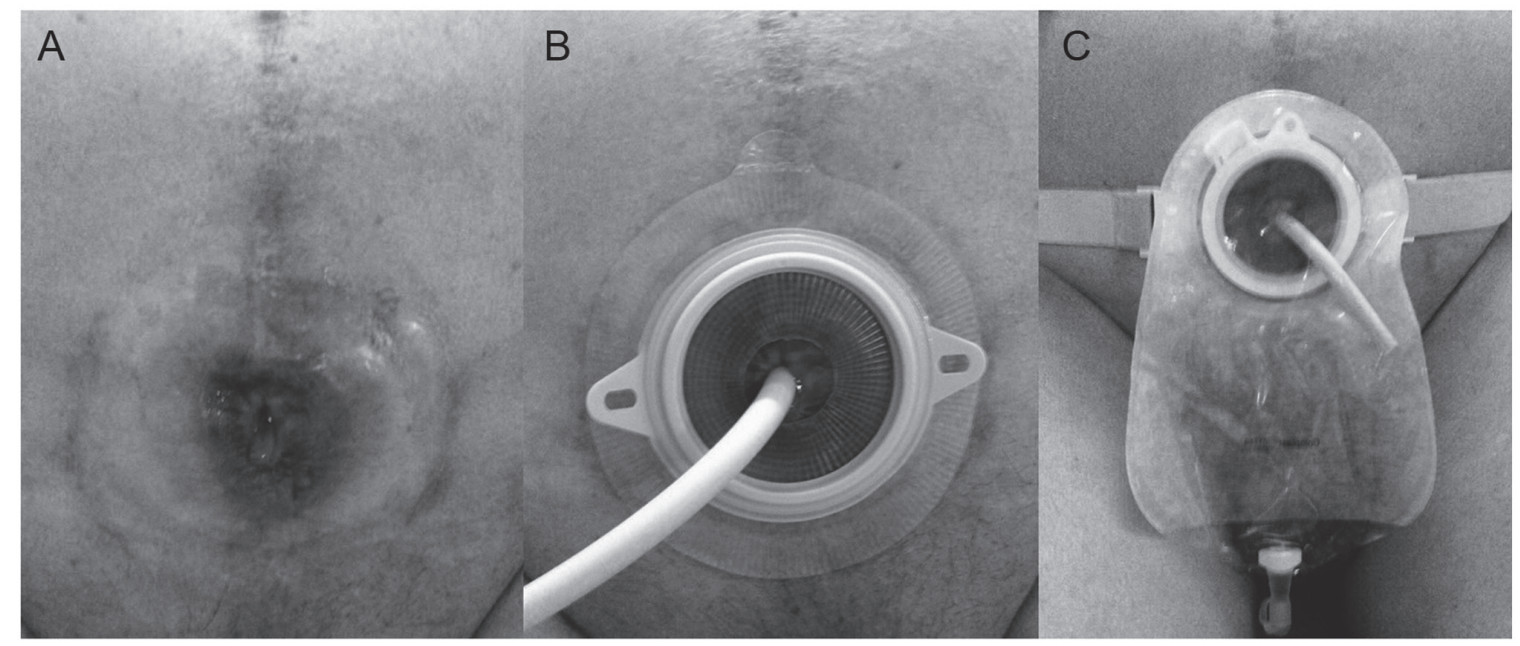

Figure 2. Images of the abdominal stoma after undiversion surgery. (A) The stoma. (B) A 26 Fr mushroom catheter was inserted into the pouch for continuous drainage. (C) The stoma was covered by ostomy pocket.

Blood potassium was found to be higher 3 months post-surgery compared with the preoperative levels, and was statistically different from 6 months post-surgery $(\mathrm{P}<0.05)$, and remained normal (between 3.5 and $5.5 \mathrm{mmol} / \mathrm{l}$ ) over the follow-up period of 1 to 2 years. Blood chlorine recovered slowly and decreased significantly over the 3 years post-operation $(\mathrm{P}<0.05)$. However, improvement in renal function was not ideal. The results of urea nitrogen improved 6 months post-operatively compared with pre-operative levels $(\mathrm{P}<0.05)$, but concentration at the 2 years follow-up was slightly higher than at the 1 year's follow-up, though still significantly lower than that pre-operatively. Serum creatinine was found to be statistically different from 6 months post-operatively compared with pre-operatively $(\mathrm{P}<0.05)$, but did not normalize (53-106 $\mu \mathrm{mol} / \mathrm{l}$ ) until 3 years post-surgery (Table I and Fig. 3).

The catheter was replaced once per month. All patients had normal defecation. No severe acidosis or electrolyte disturbances occurred during the 3 years of follow-up and the serum creatinine levels remained stable between 162 and $203 \mu \mathrm{mol} / 1$. All patients acquired satisfactory health status according to the results of EORTC QLQ C-30 survey (data not shown). Though one patient had poor life quality, most patients were satisfied with their quality of life post-surgery.

\section{Discussion}

Fisch et al (5) described a variation of ureterosigmoidostomy in 1990s. This surgery, termed the sigma-rectum or the Mainz II pouch, creates a low-pressure rectosigmoid reservoir of increased capacity. Its major advantages are the simplicity and reproducibility of the operation. Several studies have demonstrated that sigma-rectum pouch is a safe and acceptable procedure for urinary diversion, with high continence rates and a low incidence of complications $(10,11)$. Nevertheless, 
A

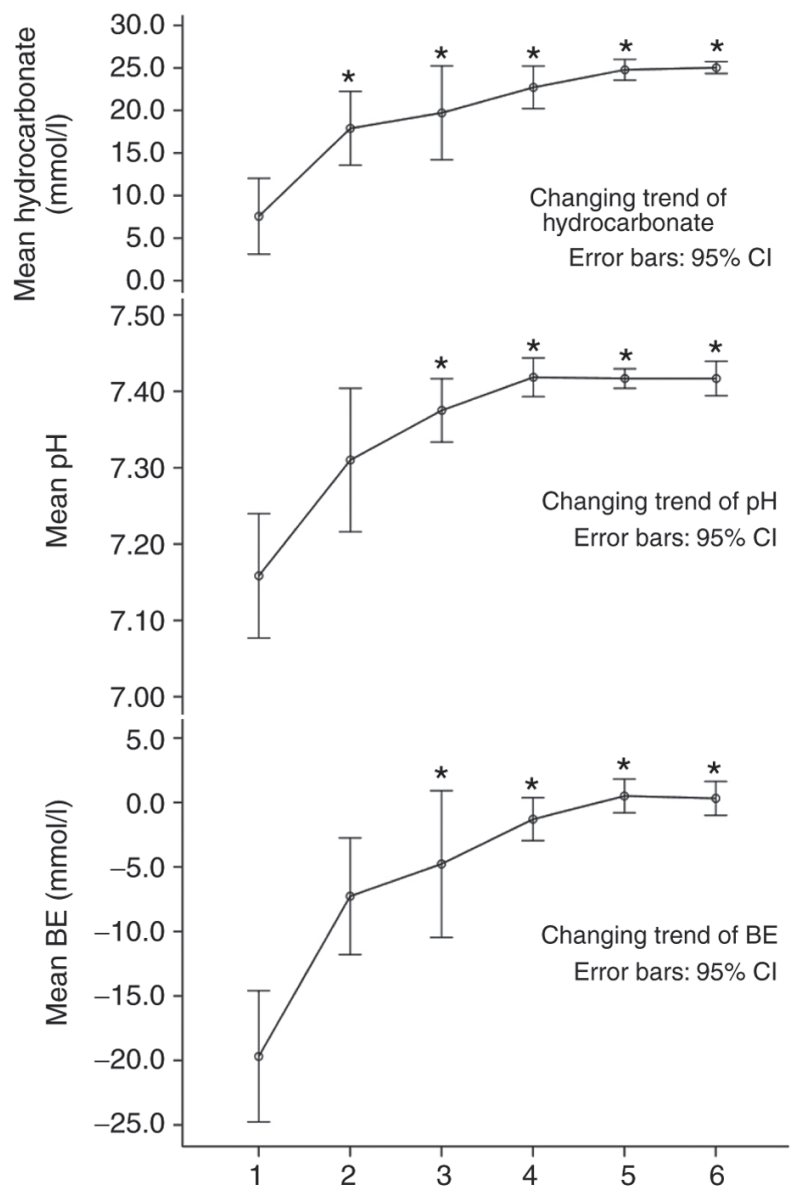

B

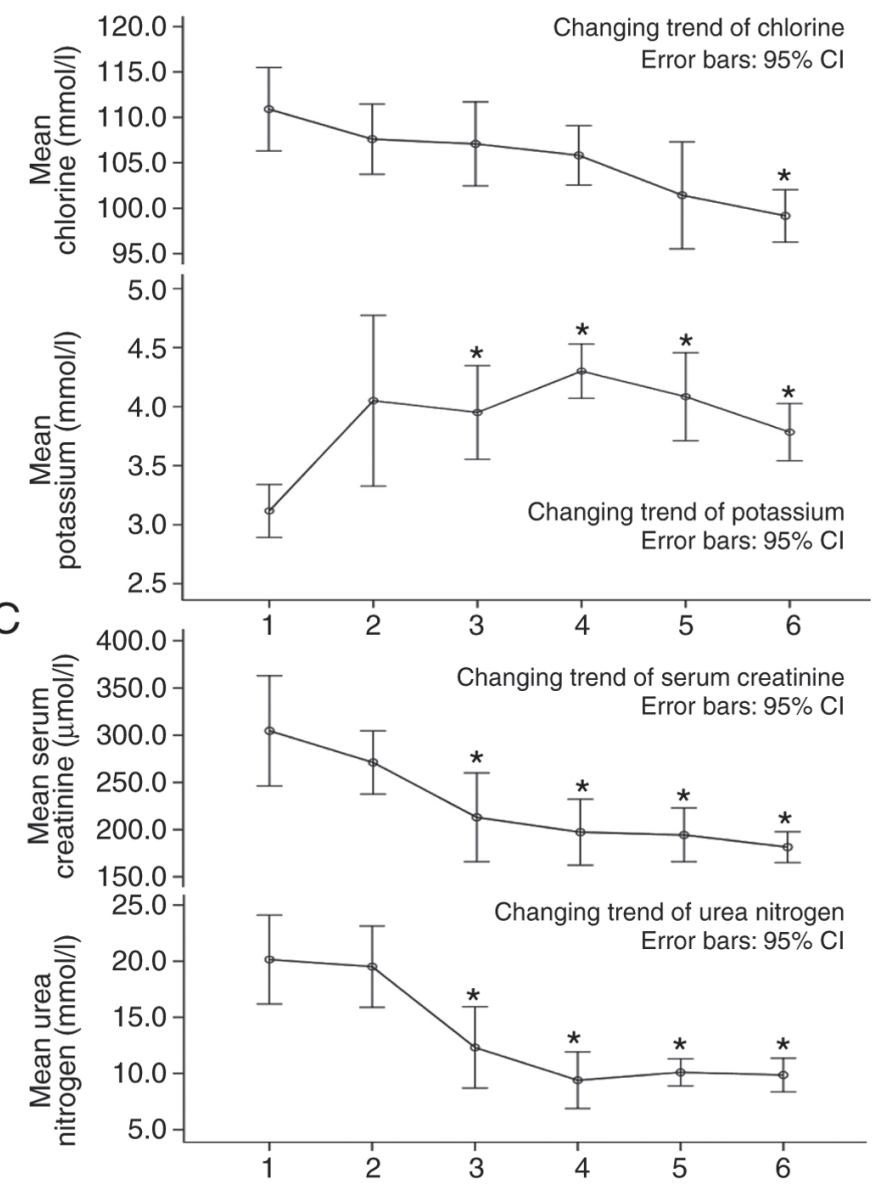

Figure 3. Statistical charts of the results for arterial blood gas analysis, serum electrolytes and renal function at 1 week preoperatively and 3 months to 3 years postoperatively. Line graphs show changing trends in parameters of (A) arterial blood gas analysis, (B) electrolyte analysis and (C) renal function between 1 week preoperatively and 3 years postoperatively. ${ }^{*} \mathrm{P}<0.05$ vs. the respective 1 week pre-operation group. 1,1 week pre-operation; 2,3 months post-operation; 3,6 months post-operation; 4, 1 year post-operation; 5, 2 years post-operation; 6, 3 years post-operation. Error bars are the $95 \%$ confidence intervals. BE, base excess.

nocturnal urinary incontinence, retrograde renal pelvis infection, ureteral-intestinal anastomotic stenosis, hyperchloremic metabolic acidosis, hypokalemia and impaired renal function are common complications occurring as a result of this procedure (12-15).

Oral administration of sodium bicarbonate has been revealed to significantly reduce the incidence of metabolic acidosis after sigma-rectum pouch surgery $(14,16)$. Most patients exhibit mild symptoms post-surgery. Severe symptoms, manifesting as fatigue, anorexia, weight loss, polydipsia or lethargy, are rare. If these symptoms persist, they can lead to severe metabolic disorders and may even be life-threatening (16). The absorption of urine in the intestine and damage to renal function are the main causes of metabolic disturbance after sigma-rectum pouch surgery. The mechanism of hyperchloremic metabolic acidosis has been revealed to be the ionized transport of ammonium, which substitutes for sodium in the $\mathrm{Na}^{+}-\mathrm{H}^{+}$antiport (12). The exchange of the weak acid $\mathrm{NH}_{4}$ for a proton is coupled with the exchange of bicarbonate for chloride. Thus, $\mathrm{NH}_{4} \mathrm{Cl}$ is absorbed across the lumen into the blood in exchange for $\mathrm{H}_{2} \mathrm{CO}_{3}\left(\mathrm{CO}_{2}\right.$ and water). Ammonium may also enter the blood from the bowel lumen through potassium channels (12). Hypokalemia or the total-body depletion of potassium is found to be more common in patients with ureterosigmoidostomy than in patients who undergo other types of urinary intestinal diversion (14). Patients most susceptible to total-body potassium depletion have been shown to be those with long-standing uncorrected metabolic acidosis (17). Potassium depletion may be due to renal potassium wasting, as a result of renal damage, osmotic diuresis and gut loss through intestinal secretion. Postoperative renal damage is thought to be related to hydronephrosis, caused by the lack of ureteral motility and the stenosis of ureterointestinal anastomosis (12).

The metabolite content of urine absorbed by the intestinal mucosa is determined by several factors, including the selected intestinal segment and its area, the residence time of urine in the pouch, urine osmotic pressure, urine $\mathrm{pH}$ value and liver function, in conjunction with overlong voiding intervals, particularly the long-term contact of urine with the intestinal mucosa due to urine reflux and storage in the descending colon at night (12).

Hyperchloremic metabolic acidosis can be treated by administering a potassium supplement, alkalizing agents and blockers of chloride transport (18). However, in cases of severe dysbolism that do not respond to conventional drug treatment, further damage to renal function can occur, forming a vicious cycle. The results of this case report suggested that surgical intervention to reduce urine absorption in the intestine and 
Table I. Results for arterial blood gas analysis, serum electrolytes and renal function at 1 week preoperatively and 3 months to 3 years postoperatively (mean $\pm \mathrm{SD})$.

\begin{tabular}{|c|c|c|c|c|}
\hline Analysis & Parameters & Follow-up time & Results & P-value \\
\hline \multirow[t]{18}{*}{ Arterial blood gas analysis } & \multirow[t]{6}{*}{$\mathrm{pH}$} & 1 week pre-operation & $7.16 \pm 0.08$ & - \\
\hline & & 3 months post-operation & $7.31 \pm 0.09$ & 1.000 \\
\hline & & 6 month post-operation & $7.36 \pm 0.04^{\mathrm{a}}$ & 0.028 \\
\hline & & 1 year post-operation & $7.42 \pm 0.02^{\mathrm{a}}$ & 0.005 \\
\hline & & 2 years post-operation & $7.42 \pm 0.01^{\mathrm{a}}$ & 0.009 \\
\hline & & 3 years post-operation & $7.42 \pm 0.02^{\mathrm{a}}$ & 0.006 \\
\hline & \multirow[t]{6}{*}{ Hydrocarbonate, mmol/1 } & 1 week pre-operation & $7.57 \pm 4.25$ & - \\
\hline & & 3 months post-operation & $17.90 \pm 4.12^{\mathrm{a}}$ & 0.026 \\
\hline & & 6 month post-operation & $19.72 \pm 5.26^{\mathrm{a}}$ & 0.022 \\
\hline & & 1 year post-operation & $22.72 \pm 2.39^{\mathrm{a}}$ & 0.005 \\
\hline & & 2 years post-operation & $24.78 \pm 1.17^{\mathrm{a}}$ & 0.001 \\
\hline & & 3 years post-operation & $25.03 \pm 0.67^{\mathrm{a}}$ & 0.001 \\
\hline & \multirow[t]{6}{*}{$\mathrm{BE}, \mathrm{mmol} / \mathrm{l}$} & 1 week pre-operation & $-19.68 \pm 4.85$ & - \\
\hline & & 3 months post-operation & $-7.27 \pm 4.31$ & 0.064 \\
\hline & & 6 month post-operation & $-4.77 \pm 5.42^{\mathrm{a}}$ & 0.022 \\
\hline & & 1 year post-operation & $-1.30 \pm 1.59^{\mathrm{a}}$ & 0.003 \\
\hline & & 2 years post-operation & $0.50 \pm 1.25^{\mathrm{a}}$ & 0.001 \\
\hline & & 3 years post-operation & $0.32 \pm 1.26^{\mathrm{a}}$ & 0.001 \\
\hline \multirow[t]{12}{*}{ Serum electrolytes } & \multirow[t]{6}{*}{ Potassium, mmol/1 } & 1 week pre-operation & $3.12 \pm 0.21$ & - \\
\hline & & 3 months post-operation & $4.05 \pm 0.69$ & 0.481 \\
\hline & & 6 month post-operation & $3.95 \pm 0.38^{\mathrm{a}}$ & 0.032 \\
\hline & & 1 year post-operation & $4.30 \pm 0.22^{\mathrm{a}}$ & 0.012 \\
\hline & & 2 years post-operation & $4.08 \pm 0.35^{\mathrm{a}}$ & 0.038 \\
\hline & & 3 years post-operation & $3.78 \pm 0.23^{\mathrm{a}}$ & 0.039 \\
\hline & \multirow[t]{6}{*}{ Chlorine, $\mathrm{mmol} / \mathrm{l}$} & 1 week pre-operation & $110.90 \pm 4.38$ & - \\
\hline & & 3 months post-operation & $107.60 \pm 3.68$ & 1.000 \\
\hline & & 6 month post-operation & $107.08 \pm 4.39$ & 1.000 \\
\hline & & 1 year post-operation & $105.82 \pm 3.12$ & 0.526 \\
\hline & & 2 years post-operation & $101.43 \pm 5.61$ & 0.184 \\
\hline & & 3 years post-operation & $99.17 \pm 2.75^{\mathrm{a}}$ & 0.038 \\
\hline \multirow[t]{12}{*}{ Renal function } & \multirow[t]{6}{*}{ Urea nitrogen, mmol/l } & 1 week pre-operation & $20.15 \pm 3.77$ & - \\
\hline & & 3 months post-operation & $19.52 \pm 3.45$ & 0.745 \\
\hline & & 6 month post-operation & $12.32 \pm 3.46^{\mathrm{a}}$ & 0.004 \\
\hline & & 1 year post-operation & $9.40 \pm 2.40^{\mathrm{a}}$ & 0.001 \\
\hline & & 2 years post-operation & $10.10 \pm 1.16^{\mathrm{a}}$ & 0.041 \\
\hline & & 3 years post-operation & $9.87 \pm 1.42^{\mathrm{a}}$ & 0.026 \\
\hline & \multirow[t]{6}{*}{ Serum creatinine, $\mu \mathrm{mol} / 1$} & 1 week pre-operation & $304.67 \pm 55.58$ & - \\
\hline & & 3 months post-operation & $271.17 \pm 31.90$ & 0.115 \\
\hline & & 6 month post-operation & $213.00 \pm 44.85^{\mathrm{a}}$ & 0.028 \\
\hline & & 1 year post-operation & $197.33 \pm 33.34^{\mathrm{a}}$ & 0.027 \\
\hline & & 2 years post-operation & $194.33 \pm 27.12^{\mathrm{a}}$ & 0.028 \\
\hline & & 3 years post-operation & $181.50 \pm 15.51^{\mathrm{a}}$ & 0.026 \\
\hline
\end{tabular}

${ }^{a} \mathrm{P}<0.05$ vs. respective data 1 week pre-operation. BE, base excess.

improve renal function might represent the best option to save the lives of these patients. Although the average serum creatinine level did not decrease to normal level (53-106 $\mu \mathrm{mol} / \mathrm{l})$ following surgery, and patients who had undergone unilateral nephrectomy due to retrograde infection may also be one of the reasons why the serum creatinine did not reach normal level.

Urinary undiversion from a sigma-rectum pouch to a cutaneous urinary stoma separates the pouch from the intestinal tract and creates a stoma on the abdominal wall for continuous 
urine discharge, without interfering with normal defecation (similar to colon conduit). This procedure reduces the surface contact area of the intestinal mucosa with urine and the residence time of urine in the intestinal tract. The metabolites from urine are then not so easily absorbed by the intestinal mucosa, so acidosis and electrolyte disturbances can be corrected. During the surgery, the stenotic ureter-pouch anastomosis was expanded, to decrease hydronephrosis, thereby improving renal function. This urinary undiversion procedure is an alternative treatment for severe complications following sigma-rectum pouch surgery.

The major preoperative preparations were correcting acidosis and electrolyte disorders and improving the general condition of patients. Bowel preparation was performed as for routine intestinal surgery. Bleeding and surrounding visceral injury can easily be caused during the urinary undiversion operation, due to adhesion and changes in local anatomical structure. However, no massive hemorrhage or other surgery-related complications were observed in the six patients. To ensure the best outcomes it was recommended that attention was paid to the following points during surgery: i) The posterior rectus sheath, if directly cut from the original incision, could easily damage the adherent intestinal canal below; therefore the rectus abdominis was pulled outward to expose the posterior rectus sheath following the opening of the anterior sheath, then the abdominal cavity was entered from the upper part of the incision without adhesion and the adherent posterior sheath and small intestine were isolated. ii) The descending colon was identified and dissected downward to the pouch, and the small intestine adhering to the pouch was separated; $\sim 5 \mathrm{~cm}$ of the distal part of the pouch was then freed in order to ease the tension-free anastomosis of the sigmoid colon with the rectum. During the separation process the blood supply of the pouch was protected. iii) The mesentery supplying blood to the pouch was moderately freed so that the pouch could be pulled out of the abdominal stoma. iv) The ureters were not isolated outside of the pouch to avoid injury and influencing the blood supply due to severe adhesion around the anastomotic stomas. v) The pouch was opened and the ureteric orifice located. Injection of $10 \mathrm{ml}$ methylene blue intravenously was performed if it was difficult to identify the orifice. The anastomotic stoma was dilated in patients with stricture and a 7 Fr single $\mathbf{J}$ tube implanted for 2 weeks to relieve hydronephrosis. vi) The cutaneous diversion was incontinent. Urine retention and infection are the main causes of stone formation (19). Therefore, a 26 Fr mushroom catheter was inserted in the stoma for constant drainage to reduce the residence time of urine in the pouch.

In conclusion, urinary undiversion from sigma-rectum pouch to cutaneous urinary stoma exhibited a therapeutic effect in six patients with severe metabolic disorders after sigma-rectum pouch surgery. However, the long-term effectiveness of this procedure is yet to be confirmed and more data are needed to establish its benefit. Of the hundreds of patients who have undergone sigma-rectum pouch surgery at BenQ Medical Center, only very few have been observed to suffer from serious metabolic disorders, which are complications that need attention and timely correction. Surgical treatment is recommended to improve patient quality of life, and urinary undiversion surgery may be an effective option.

\section{Acknowledgements}

Not applicable.

\section{Funding}

Funding was obtained from Nanjing Medical Science and Technique Development Foundation (grant no. QRX17099).

\section{Availability of data and materials}

All data generated or analyzed during this study are included in this published article.

\section{Authors' contributions}

HS and HW had full access to all the data in the study and were responsible for the integrity and the accuracy of the data analysis. KL and WW were involved in data analysis. HY was involved in the implementation of surgery and the design of research methods.

\section{Ethics approval and consent to participate}

All procedures performed in this study involving human participants were in accordance with the ethical standards of the institutional and/or national research committee and with the 1964 Helsinki declaration (20) and its later amendments or comparable ethical standards. Written informed consent was obtained from all patients.

\section{Patient consent for publication}

All patients provided written informed consent.

\section{Competing interests}

The authors declare that they have no competing interests.

\section{References}

1. Stein JP, Lieskovsky G, Cote R, Groshen S, Feng AC, Boyd S, Skinner E, Bochner B, Thangathurai D, Mikhail M, et al: Radical cystectomy in the treatment of invasive bladder cancer: Long-term results in 1,054 patients. J Clin Oncol 19: 666-675, 2001.

2. World Health Organization (WHO) Consensus Conference in Bladder Cancer, Hautmann RE, Abol-Enein H, Hafez K, Haro I, Mansson W, Mills RD, Montie JD, Sagalowsky AI, Stein JP, Stenzl A, Studer UE and Volkmer BG: Urinary diversion. Urology 69 (Suppl 1): 17-49, 2007.

3. Lee RK, Abol-Enein H, Artibani W, Bochner B, Dalbagni G, Daneshmand S, Fradet Y, Hautmann RE, Lee CT, Lerner SP, et al: Urinary diversion after radical cystectomy for bladder cancer: Options, patient selection, and outcomes. BJU Int 113: 11-23, 2014.

4. Lee DJ, Tyson MD and Chang SS: Conduit Urinary Diversion. Urol Clin North Am 45: 25-36, 2018.

5. Fisch M, Wammack R, Müller SC and Hohenfellner R: The Mainz pouch II (sigma rectum pouch). J Urol 149: 258-263, 1993.

6. Djokić JH, Milojević B, Pejčić T, Aćimović M, Stamenković V and Džamić Z: Sigma-rectum pouch (Mainz pouch II). Acta Chir Iugosl 61: 29-34, 2014.

7. Hadzi-Djokic JB and Basic DT: A modified sigma-rectum pouch (Mainz pouch II) technique: Analysis of outcomes and complications on 220 patients. BJU Int 97: 587-591, 2006.

8. Zhvania G, Mshvildadze Sh, Managadze G and Khvadagiani G: Results of radical cystectomy with Mainz pouch II diversion (single institution experience). Georgian Med News 211: 7-13, 2012. 
9. Fayers PM, Aaronson NK, Bjordal K, Groenvold M, Curran D, Bottomley A: The EORTC QLQ-C30 Scoring Manual (3rd edition). European Organisation for Research and Treatment of Cancer, Brussels, 2001.

10. Atta MA: Detubularized isolated ureterosigmoidostomy: Description of a new technique and preliminary results. J Urol 156 915-919, 1996.

11. Gilja I, Kovacić M, Radej M, Kosuta D, Bakula B and Goles L: The sigmoidorectal pouch (Mainz pouch II). Eur Urol 29: 210-215, 1996.

12. Dahl DM and McDougal WS: Use of Intestinal Segments in Urinary Diversion. In: Campbell Walsh-Urology. Wein AJ, Kavoussi LR, Novick AC, Partin AW and Peters CA (eds): 10th edition. Saunders Elsevier, Philadelphia, pp2441-2449, 2012

13. McDougal WS, Stampfer DS, Kirley S, Bennett PM and Lin CW: Intestinal ammonium transport by ammonium and hydrogen exchange. J Am Coll Surg 181: 241-248, 1995.

14. Sun B, Yan JM, Li JY, Guo HQ, Hong Q, Yao ZY,Zhou GB, Pan GX and Li XC: Long-term follow-up on the effects of sigmoid-rectal pouch for urinary diversion. Urol J 11: 1629-1635, 2014
15. Obek C, Kural AR, Ataus S, Coskuner E, Demirkesen O, Citç A, Onder AU and Solok V: Complications of the Mainz pouch II (sigma rectum pouch). Eur Urol 39: 204-211, 2001.

16. Geist RW and Ansell JS: Total body potassium in patients after ureteroileostomy. Surg Gynecol Obstet 113: 585-590, 1961.

17. Stein R, Fisch M, Andreas J, Bockisch A, Hohenfellner R and Thüroff JW: Whole-body potassium and bone mineral density up to 30 years after urinary diversion. Br J Urol 82: 798-803, 1998.

18. Kraut JA and Madias NE: Metabolic acidosis: Pathophysiology, diagnosis and management. Nat Rev Nephrol 6: 274-285, 2010.

19. Ferriero M, Guaglianone S, Papalia R, Muto GL, Gallucci M and Simone G: Risk assessment of stone formation in stapled orthotopic ileal neobladder. J Urol 193: 891-896, 2015.

20. World Medical Association Declaration of Helsinki: World Medical Association Declaration of Helsinki. JAMA 310: 2191, 2013.

This work is licensed under a Creative Commons

Attribution-NonCommercial-NoDerivatives 4.0 International (CC BY-NC-ND 4.0) License. 